\title{
PENINGKATKAN KEMAMPUAN PEMAHAMAN MATEMATIS MELALUI PENGEMBANGAN MEDIA PEMBELAJARAN MATEMATIKA BERBANTUAN MACROMEDIA FLASH PADA SISWA KELAS VI SD MATERI BANGUN DATAR
}

\author{
OLEH: \\ PATRI JANSON SILABAN ${ }^{1}$, ASNITA HASIBUAN ${ }^{2}$ \\ (PGSD UNIVERSITAS KATOLIK SANTO THOMAS MEDAN, UNIVERSITAS KATOLIK SANTO THOMAS MEDAN)
}

\begin{abstract}
The problem in this research is learning rarely uses media in learning, students' mathematical understanding ability is still low in mathematics learning flat-build material, lack of learning media. This study aims to determine the relationship of the development of Macromedia Flash-assisted mathematics learning media related to flat material. This research method uses research and development (Research and Development). The 4-D device development model consists of 4 stages of development, namely Define, Design, Develop and Disseminate or adapted into a 4-D model, namely defining, designing, developing and disseminating. In the field trials the average pretest score is 68.24 while the average posttest score is 86.76. An average increase of 18.52 .

The minimum gain value is 0.62 while the maximum gain value is 1.00 . In the test of the spread of the average pretest value is 60.33 while the average posttest score is 81.33 . An average increase of 21 . The minimum gain value is 0.77 while the maximum gain value is 0.83 . Based on these data, the development of mathematics learning media assisted by macromedia flash has experienced a significant increase in students' mathematical understanding abilities.
\end{abstract}

\section{Keywords: Macromedia Flash Assisted Mathematics Learning Media, Mathematical Understanding Ability}

\section{PENDAHULUAN}

\section{Latar Belakang}

Proses belajar merupakan suatu proses yang kompleks yang terjadi pada diri setiap orang sepanjang hidupnya, proses belajar itu terjadi karena adanya interaksi antara seseorang dengan lingkungannya. Oleh karena itu, belajar dapat terjadi dimana saja dan kapan saja. Salah satu pertanda bahwa seseorang itu telah belajar adalah dengan adanya perubahan tingkat pengetahuan, keterampilan dan sikapnya. Dalam hal ini, matematika juga perlu dipelajari karena dapat menambah tingkat pengetahuan, keterampilan, sikap terhadap belajar siswa. 
Pada kenyataan di lapangan proses pembelajaran matematika yang dilaksanakan pada saat ini belum memenuhi harapan para guru sebagai pengembangan strategi pembelajaran di kelas. Siswa mengalami kesulitan dalam belajar matematika, khususnya dalam menyelesaikan soal yang berhubungan dengan kemampuan pemahaman matematis siswa. Dengan demikian, kemampuan pemahaman matematis merupakan faktor yang sangat penting bagi perkembangan kognitif siswa dan mempengaruhi motivasi belajar matematika siswa. Hal ini dapat dilihat dalam mengukur kemampuan pemahaman matematis siswa sebagai berikut: Luas sebuah persegi adalah $64 \mathrm{~cm}^{2}$. Berapakah $\mathrm{cm}$ kah sisi bangun persegi tersebut? Dalam penyelesaikan soal tersebut diharapkan siswa menyelesaikan dengan mencari panjang sisi persegi, namun kebanyakan siswa tidak bisa menyelesaikan soal karena siswa menyelesaikan soal tersebut dengan memasukkan angka yang ada dalam soal kedalam rumus luas persegi. Hal ini siswa kurang memahami langkah-langkah penyelesaian masalah karena siswa tidak memiliki kemampuan pemahaman matematis, dimana seharusnya dari tahap perencanaan siswa menyelesaikannya dengan memodelkan dahulu kedalam bentuk matematika sesuai dengan soal, kemudian menyelesaikannya dengan mencari panjang sisi persegi.

Secara khusus, tujuan pembelajaran Matematika di sekolah dasar, sebagaimana yang disajikan oleh Depdiknas (dalam Susanto 2013:190), sebagai berikut: a) memahami konsep matematika, menjelaskan keterkaitan antar konsep, dan mengaplikasikan konsep atau algoritma, b) menggunakan penalaran pada pola dan sifat, melakukan manipulasi matematika dalam generalisasi, menyusun bukti, atau menjelaskan gagasan dan pernyataan matematika, c) memecahkan masalah yang meliputi kemampuan memahami masalah, merancang model matematika, menyelesaikan model, dan menafsirkan solusi yang diperoleh, d) mengomunikasikan gagasan dengan simbol, tabel, diagram, atau media lain untuk menjelaskan keadaan atau masalah, e) mamiliki sikap menghargai penggunaan 
matematika dalam kehidupan sehari-hari. Guru juga diharapkan dapat menggunakan media pembelajaran yang sesuai dengan keadaan siswa agar dapat meningkatkan kemampuan pemahaman matematis pada mata pelajaran matematika salah satu diantaranya dengan menggunakan media berbantuan macromedia flash. Macromedia flash merupakan cara belajar yang efektif, efesien, dan menyenangkan.

Untuk menyikapi permasalahan yang timbul dalam proses pembelajaran matematika, perlu dicari solusi pendekatan pembelajaran yang dapat mengakomodasi pengembangan media pembelajaran matematika berbantuan Macromedia Flash untuk meningkatkan kemampuan pemahaman matematis siswa kelas VI SD semakin meningkat sehingga hasil belajar siswa juga semakin baik.

\section{Identifikasi Masalah}

Berdasarkan latar belakang di atas, yang menjadi identifikasi masalah dalam penelitian ini adalah:

1. Siswa kurang tertarik dalam belajar Matematika

2. Kurangnya kemampuan pemahaman siswa

3. Guru tidak terampil dalam pengembangan media pembelajaran

\section{Batasan Masalah}

Adapun yang menjadi batasan masalah dalam penelitian ini adalah:

Pengembangan media pembelajaran matematika berbantuan Macromedia Flash untuk meningkatkan kemampuan pemahaman matematis siswa kelas VI SD pada materi bangun datar.

\section{Perumusan Masalah}

Adapun yang menjadi rumusan masalah dalam penelitian ini adalah: Bagaimana peningkatkan kemampuan pemahaman matematis siswa melalui media pembelajaran matematika berbantuan macromedia flash pada siswa kelas VI SD pada materi bangun datar?

\section{Tujuan Penelitian}


Adapun yang menjadi tujuan dalam penelitian ini adalah: Untuk mengetahui peningkatkan kemampuan pemahaman matematis siswa melalui media pembelajaran matematika berbantuan macromedia flash pada siswa kelas VI SD pada materi bangun datar.

\section{METODE PENELITIAN}

\section{Jenis Penelitian}

Penelitian ini termasuk dalam penelitian dan pengembangan (Research and Development). Sebagaimana pendapat Sugiyono (2010) bahwa R\&D adalah metode penelitian yang digunakan untuk menghasilkan produk tertentu dan menguji keefektifan produk tersebut. Metode ini digunakan dengan tujuan mengembangkan media pembelajaran matematika pada kelas VI SD terkait materi bangun datar.

\section{Lokasi Penelitian}

Penelitian ini dilaksanakan di SD Swasta Methodist 12 Medan, terletak di Jl. Panca No. 28 Marendal Kelurahan Harjosari II, Kecamatan Medan Amplas.

\section{Subjek dan Objek Penelitian}

Subjek dari penelitian ini adalah kelas VI SD Swasta Methodist 12 Medan Tahun Ajaran 2019/2020. Objek penelitian ini adalah media pembelajaran matematika berbantuan macromedia flash.

\section{Variabel Penelitian}

Adapun variabel dalam penelitian ini adalah sebagai berikut :

1. Validitas ketepatan materi pembelajaran matematika pada kelas VI terkait bangun datar.

2. Validitas ketepatan desain instruksional

3. Validitas ketepatan media pembelajaran matematika berbantuan macromedia flash

4. Kemampuan pemahaman matematis siswa yang diukur dengan tes uraian terkait materi bangun datar.

5. Tanggapan siswa terhadap media pembelajaran matematika berbantuan macromedia flash materi bangun datar. 
6. Respon siswa terhadap media pembelajaran matematika berbantuan macromedia flash materi bangun datar.

7. Tanggapan guru media pembelajaran matematika berbantuan macromedia flash materi bangun datar.

\section{Model Pengembangan}

Pengembangan media pembelajaran matematika adalah suatu proses untuk menentukan atau menciptakan suatu kondisi tertentu yang menyebabkan siswa dapat berinteraksi sehingga terjadi perubahan tingkah laku. Salah satu model yang sesuai untuk mengembangkan media pembelajaran adalah model pembelajaran 4D.

Model pengembangan perangkat 4-D terdiri dari 4 tahap pengembangan yaitu Define, Design, Develop dan Disseminate atau diadaptasikan menjadi model 4-D yaitu pendefinisian, perancangan, pengembangan dan penyebaran. Sebagaimana Reynolds dalam Rochmad (2012:67) mengemukakan penjelasan tahapan pengembangan model Four-D yaitu :

a. Define (Pendefenisian)

Tujuan dari tahap pendefenisian ini adalah untuk menetapkan dan mendefenisikan hal yang dibutuhkan dalam instruksional. Ada 5 hal yang ditempuh dalam tahap ini yaitu :

1. Front-end analysis (analisis awal dan akhir)

Menyelidiki tentang masalah dasar yang dihadapi oleh guru mengenai tingkat kinerja guru. Selama penyelidikan inilah alternatif pemecahan yang lebih baik dan lebih efisien dapat dipertimbangkan

2. Learner analysis (analisis siswa)

Mengidentifikasi karakter dari siswa yang akan dihadapi. Karakter yang dimaksudkan adalah kompetensi dan latar belakang pengalaman belajar siswa, perilaku umum terhadap topik pembelajaran, pemilihan media, format dan bahasa yang akan digunakan.

3. Task analysis (analisis tugas) 
Mengidentifikasi keterampilan utama yang dibutuhkan dan menguraikannya ke dalam keterampilan-keterampilan yang lebih khusus yang perlu dan cukup.

4. Concept analysis (analisis konsep)

Mengidentifikasi konsep-konsep utama yang harus diajarkan, menata konsep ke dalam suatu hirarki dan merinci sifat atau ciri-ciri dari masing-masing konsep. Analisis ini membantu mengidentifikasi sekumpulan pemikiran tentang contoh yang dapat dibawakan dalam pengembangan.

5. Speccifying instructional objectives (menetapkan tujuan pembelajaran) Mengkonversi hasil analisis tugas dan analisis konsep menjadi tujuan berupa perilaku yang diharapkan. Kumpulan tujuan ini menjadi dasar dalam penyusunan tes, perancangan dan selanjutnya tujuan ini diintegrasikan ke dalam materi pelajaran.

b. Design (perancangan)

Tujuan dari tahap ini adalah merancang awal dari materi pembelajaran. Tahap ini dapat dimulai jika tujuan dari materi pelajaran telah ditetapkan pada tahap sebelumnya. Terdapat empat langkah pada tahap ini yaitu :

1. Constructing criterion test (menyusun kriteria referensi tes)

Langkah ini merupakan jembatan yang menghubungkan tahap I dan II. Kriteria yang dikembangkan mengkonversi tujuan menjadi kerangka dari materi pembelajaran.

2. Media selection (pemilihan media)

Pemilihan media yang sesuai untuk menyajikan isi dari pembelajaran.

Proses ini mencakup sumber, rencana penyebaran dan sifat-sifat media.

3. Format selection (pemilihan format)

Langkah ini terkait dengan pemilihan media sebelumnya. Format pembelajaran mengacu pada komunikasi media, strategi mengajar dan teknik penggunaan. Pemilihan format ini tergantung pada format visual, audiovisual, non verbal dan sebagainya. 


\section{Initial design}

Menyajikan hal-hal dasar dari pembelajaran melalui media yang tepat dan dalam urutan yang sesuai. Langkah ini juga mencakup menyusun berbagai kegiatan belajar seperti membaca buku, mewawancarai siswa tertentu dan menerapkan keahlian yang berbeda dengan memperhatikan setiap siswa.

\section{c. Develop (Pengembangan)}

Tujuan dari langkah pengembangan ini adalah memodifikasi materi pembelajaran pada draf awal. Hasil dari tahap perancangan harus dipertimbangkan sebagai versi awal sehingga diperlukan versi akhir yang efektif. Ada dua langkah dalam tahap ini yaitu :

\section{Expert appraisal}

Merupakan teknik untuk memperoleh saran untuk memperbaiki materi. Sejumlah ahli diminta untuk mengevaluasi materi dari sudut pandang pembelajaran dan teknik. Berbasarkan umpan balik dari ahli inilah draf awal yang telah dimodifikasi.

\section{Developmental testing}

Mengujicobakan materi terhadap siswa untuk menetapkan bagian yang memerlukan revisi. Berdasarkan respon siswa dan komentar siswa, materi dapat dimodifikasi. Siklus menguji dan merevisi ulang dilakukan sehingga diperoleh materi yang berlaku konsisten dan efektif.

\section{d. Disseminate (Penyebaran)}

Draf final dari materi pembelajaran diperoleh jika fase uji pengembangan menunjukkan hasil yang konsisten dari ahli memberi komentar yang positif. Pada dikenal tiga langkah yaitu:

1. Validating testing

Pada langkah ini materi digunakan pada kondisi tiruan yang mendemonstrasikan siapa yang belajar, apa yang dipelajari, pada kondisi yang bagaimana dan berapa banyak waktu yang digunakan. 
Pada langkah ini materi juga dibawakan pada pemeriksaan profesional untuk memperoleh pendapat yang objektif mengenai kecukupan dan relevansinya.

2. Packaging

Produse dan distributor dipilih dan bekerja sama secara kooperatif untuk mengemas materi dalam bentuk yang dapat diterima.

\section{Diffusion and adopting}

Merupakan usaha khusus yang dibutuhkan untuk menyebarkan materi secara luas pada guru dan siswa dalam bentuk yang dapat diterima.

Modifikasi dari tahap-tahap pengembangan media pembelajaran dapat dilihat pada gambar 4.1 sebagai berikut!

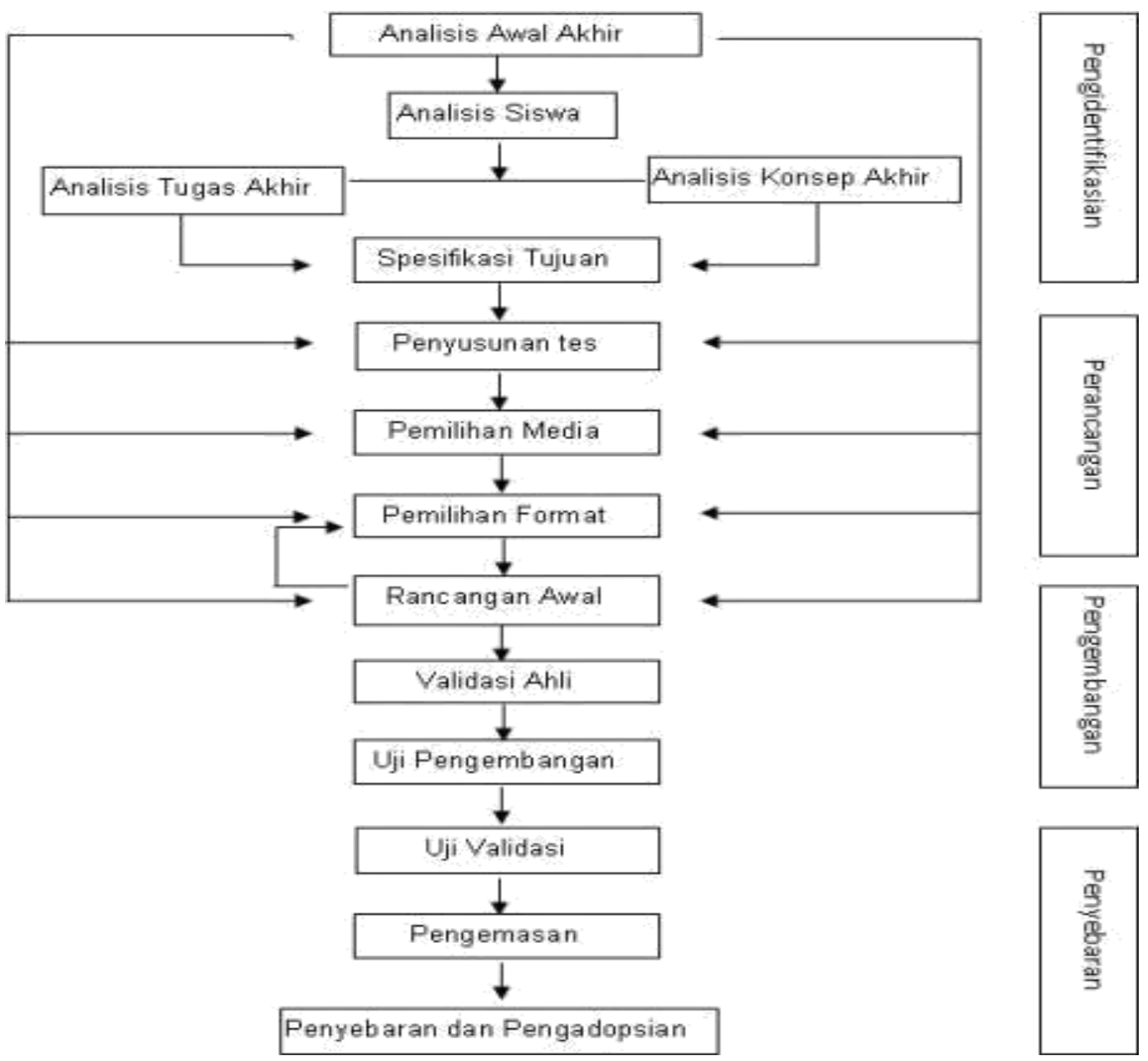

Bagan 4.1 Modifikasi Model Pengembangan Media Pembelajaran 4-D. 


\section{Instrumen Pengumpulan Data}

Instrumen pengumpulan data yang digunakan sebagai berikut:

a. Lembar Angket Penilaian

Lembar angket dalam penelitian ini adalah lembar penilaian atau saran terhadap produk atau media pembelajaran untuk penyempurnaan media yang dihasilkan dalam pelaksanaan penelitian.

Adapun lembar angket terdiri dari :

1. Lembar angket untuk ahli materi yaitu penilaian terhadap kualitas materi pembelajaran dan pengembangan aspek sistem penyampaian pembelajaran

2. Lembar angket untuk ahli desain instruksional pembelajaran yaitu penilaian terhadap kualitas desain pembelajaran dan teknis dari media pembelajaran

3. Lembar angket untuk ahli media yaitu kualitas rekayasa perangkat lunak (software) yang dikembangkan khususnya media pembelajaran

4. Lembar angket untuk siswa yaitu tanggapan terhadap penggunaan dan manfaat media pembelajaran yang dikembangkan

5. Lembar angket untuk respon siswa yaitu tanggapan terhadap yang menunjukkan rasa senang atau tidak terhadap media pembelajaran.

6. Lembar angket persepsi guru yaitu tanggapan guru terhadap penggunaan dan manfaat media pembelajaran yang dikembangkan

\section{Ujicoba Instrumen Tes}

\section{Validitas Tes}

Untuk mengukur tes digunakan korelasi Product Moment Pearson (Arikunto, 2009:72) dengan mengkorelasikan antara skor yang didapat siswa pada suatu butir soal dengan skor total. Rumus yang digunakan adalah :

$$
\mathrm{Rxy}=\frac{N \Sigma x y-(\Sigma x)(\Sigma y)}{\sqrt{\left(N \Sigma X^{2}-\Sigma X\right)^{2}\left(N \Sigma Y^{2}-\Sigma Y\right)^{2}}} \quad \text { (Arikunto, 2014: 231) }
$$

Keterangan :

$$
\begin{array}{ll}
\mathrm{Rxy} & =\text { Koefisien korelasi } \mathrm{x} \text { dan } \mathrm{y} \\
\mathrm{N} & =\text { Jumlah responden / banyak siswa peserta tes } \\
\mathrm{X} & =\text { Jumlah skor diperoleh siswa untuk tiap item soal } \\
\mathrm{Y} & =\text { Jumlah skor total yang benar }
\end{array}
$$

Untuk mengetahui signifikansi korelasi yang didapat, diuji dengan rumus $\mathrm{t}$ : 


$$
t=r_{x y} \sqrt{\frac{N-2}{1-\left(r_{x y}\right)^{2}}}
$$

Dengan;

$\mathrm{t} \quad=$ daya beda uji $\mathrm{t}$

$\mathrm{N} \quad=$ jumlah subjek

$r_{x y}=$ koefisien krelasi antara skor butir dengan skor total

Menentukan validitas suatu butir soal. Kriteria yang harus dipenuhi agar suatu butir soal dikatakan valid adalah jika $t_{\text {hitung }}>t_{\text {tabel }}$ dengan $t_{\text {tabel }}=t_{(1-\alpha)(d k)}$ untuk $\mathrm{dk}=N-2$ dan (taraf signifikansi) dipilih 5\%.

Untuk menginterpetasikan koefisien reliabilitas suatu alat evaluasi (Arikunto, 1999) memberikan kriteria tabel 2.1 sebagai berikut:

Tabel 2.1 Kriteria Validitas

\begin{tabular}{|l|l|}
\hline $0,80-1,00$ & Sangat tinggi \\
\hline $0,60-0,79$ & Tinggi \\
\hline $0,40-0,59$ & Cukup \\
\hline $0,20-0,39$ & Rendah \\
\hline $0,00-0,19$ & Sangat rendah \\
\hline
\end{tabular}

\section{Reliabilitas Tes}

Realiabilitas instrumen tes dihitung untuk mengetahui ketetapan hasil tes. Untuk menghitung reliabilitas butir tes ini digunakan rumus yang sesuai dengan bentuk tes uraian (essay), yaitu rumus alpha sebagai berikut:

$$
\mathrm{R} 11=\left(\frac{n}{n-1}\right)\left(\frac{s^{2}-\Sigma p q}{s^{2}}\right)
$$

Keterangan :

R11 = Reliabilitas tes

$\mathrm{p} \quad=$ Proporsi subjek yang menjawab item dengan benar

$\mathrm{q}=$ = Proporsi subjek yang menjawab item dengan salah

$\Sigma \mathrm{pq} \quad=$ Jumlah hasil perkalian antara $\mathrm{p}$ dan $\mathrm{q}$

$\mathrm{n} \quad=$ Banyak nya item

$\mathrm{S} \quad=$ Standar deviasi 
Rumus untuk mencari standar deviasi sebagai berikut :

$$
\mathrm{SD}=\sqrt{\frac{\Sigma f x^{2}}{N}}
$$

Keterangan :

$\mathrm{SD} \quad=$ Standar Deviasi

$\Sigma \mathrm{fx}^{2}=$ jumlah perkalian antara frekuensi masing - masing interval dengan

$$
\text { frekuensi yang dikuadratkan }
$$

$\mathrm{N} \quad=$ jumlah sampel

Interpretasi nilai $\mathrm{r}_{11}$ mengacu pada Jihad dan Haris (2012: 180) dipaparkan pada tabel 2.2.

Tabel 2.2 Kualifikasi Koefisien Korelasi

\begin{tabular}{|l|l|l|}
\hline No & Koefisien Korelasi & Kualifikasi \\
\hline 1 & $0,80<r_{x y} \leq 1,00$ & Derajat sangat tinggi \\
\hline 2 & $0,60<r_{x y} \leq 0,80$ & Derajat tinggi \\
\hline 3 & $0,40<r_{x y} \leq 0,60$ & Derajat cukup \\
\hline 4 & $0,20<r_{x y} \leq 0,40$ & Derajat rendah \\
\hline 5 & $r_{x y} \leq 0,40$ & Derajat sangat rendah \\
\hline
\end{tabular}

\section{Teknik Analisa Data}

Teknik analisis data dalam penelitian ini sebagai berikut :

\section{Validasi Media}

\section{Validasi Ahli}

Analisis data dalam penelitian ini menggunakan analisis deskriptif kuantitatif. Selanjutnya dari data yang diperoleh hasilnya dirata-rata dan digunakan untuk menilai kualitas produk yang dikembangkan. Kriteria produk akan dikonversikan menjadi nilai dengan skala lima menggunakan Skala Likert yang dianalisis secara deskriptif (skor rata-rata dan persentase) yaitu menghitung persentase indikator dari setiap kategori pada media macromedia flash yang telah dikembangkan dengan menggunakan rumus :

$$
\text { Skor empiris }=\frac{\text { Jumlah Skor yang diperoleh }}{\text { Jumlah skor ideal seluruh item }} \times 100 \%
$$


Selanjutnya persentase kriteria validitas dapat dilihat pada Tabel 2.3

Tabel 2.3 Persentase Kriteria Kesesuaian Indikator

\begin{tabular}{|c|c|c|c|}
\hline No & Kriteria & Interval Persentase & Keterangan \\
\hline 1 & Sangat baik & $85 \% \leq \mathrm{X} \leq 100 \%$ & Tidak perlu revisi \\
\hline 2 & Baik & $75 \% \leq \mathrm{X} \leq 84 \%$ & Tidak perlu revisi \\
\hline 3 & Sedang & $65 \% \leq \mathrm{X} \leq 74 \%$ & Direvisi \\
\hline 4 & Kurang & $55 \% \leq \mathrm{X} \leq 64 \%$ & Direvisi \\
\hline 5 & Sangat kurang baik & $0 \% \leq \mathrm{X} \leq 54 \%$ & Direvisi \\
\hline
\end{tabular}

Sedangkan dalam perhitungan tingkat kelayakan pada media macromedia flash sebagai media pembelajaran, penilaiannya sebagai berikut :

Tabel 2.4 Persentase Kri teria Tingkat Kelayakan

\begin{tabular}{|c|c|c|}
\hline No & Tingkat Kelayakan & Skor \\
\hline $\mathbf{1}$ & Tidak layak & $65 \%$ \\
\hline $\mathbf{2}$ & Kurang layak & $65 \%-74 \%$ \\
\hline $\mathbf{3}$ & Layak & $75 \%-84 \%$ \\
\hline $\mathbf{4}$ & Sangat layak & $85 \%-100 \%$ \\
\hline
\end{tabular}

\section{Tanggapan Guru dan Siswa}

Data mengenai tanggapan guru dan siswa terhadap media macromedia flash sebagai media pembelajaran yang dikembangkan, diberikan angket setelah selesai pembelajaran materi Bangun datar. Kriteria penilaian kesesuaian dengan indikator tanggapan guru dan siswa terhadap media macromedia flash sebagai media pembelajaran dapat dilihat pada tabel 2.5 berikut :

Tabel 2.5 Persentase Kriteria Tanggapan Guru dan Siswa sesuai Indikator

\begin{tabular}{|c|c|c|c|}
\hline No & Kriteria & Interval Persentase & Keterangan \\
\hline 1 & Sangat baik & $85 \% \leq \mathrm{X} \leq 100 \%$ & Tidak perlu revisi \\
\hline 2 & Baik & $75 \% \leq \mathrm{X} \leq 84 \%$ & Tidak perlu revisi \\
\hline 3 & Sedang & $65 \% \leq \mathrm{X} \leq 74 \%$ & Direvisi \\
\hline 4 & Kurang & $55 \% \leq \mathrm{X} \leq 64 \%$ & Direvisi \\
\hline
\end{tabular}




\begin{tabular}{|c|c|c|c|}
\hline 5 & Sangat kurang baik & $0 \% \leq \mathrm{X} \leq 54 \%$ & Direvisi \\
\hline
\end{tabular}

\section{Respon Siswa}

Data mengenai respon siswa terhadap media macromedia flash sebagai media pembelajaran yang dikembangkan, diberikan angket setelah selesai pembelajaran materi bangun datar. Kriteria penilaian kesesuaian dengan indikator respon siswa terhadap media macromedia flash sebagai media pembelajaran dapat dilihat pada tabel 2.6 berikut :

Adapun kriteria respon siswa sebagai berikut (Tamrin,2003:90)

\begin{tabular}{|c|c|c|}
\hline No & Interval Persentase & Keterangan \\
\hline 1 & $3,5(87.6)<$ skor rata-rata $\leq 4(100)$ & Sangat Positif \\
\hline 2 & $2,5(62.6) \leq$ skor rata-rata $\leq 3,5(87.5)$ & Positif \\
\hline 3 & $1(0) \leq$ skor rata-rata $\leq 2,5(62.5)$ & Negatif \\
\hline
\end{tabular}

\section{Validasi RPP}

Validasi RPP dilakukan berdasarkan pada 3 aspek penilaian yaitu format, bahasa dan isi. Persentase rata-rata skor untuk validasi RPP dapat dilihat pada tabel 2.7 berikut :

Tabel 2.7 Persentase Skor Rerata Validasi RPP

\begin{tabular}{|c|c|c|c|}
\hline No & Kriteria & Interval Persentase & Keterangan \\
\hline 1 & Sangat baik & $85 \% \leq \mathrm{X} \leq 100 \%$ & Tidak perlu revisi \\
\hline 2 & Baik & $75 \% \leq \mathrm{X} \leq 84 \%$ & Tidak perlu revisi \\
\hline 3 & Sedang & $65 \% \leq \mathrm{X} \leq 74 \%$ & Direvisi \\
\hline 4 & Kurang & $55 \% \leq \mathrm{X} \leq 64 \%$ & Direvisi \\
\hline 5 & Sangat kurang baik & $0 \% \leq \mathrm{X} \leq 54 \%$ & Direvisi \\
\hline
\end{tabular}

\section{Peningkatan Kemampuan Pemahaman Matematis Siswa}

Untuk mengetahui peningkatan kemampuan pemahaman matematis siswa dilakukan tes awal (pretest) dan tes akhir (posttest). Hasil dari kedua tes tersebut dihitung dengan $\mathrm{N}$-gain

$$
(g)=\frac{(\text { gain })}{(\text { gain })_{\operatorname{Max}}}=\frac{(\text { postest })-(\text { pretest })}{100-(\text { pretest })}
$$


Tabel 2.8 Kriteria peningkatan ditentukan sebagai berikut :

\begin{tabular}{|l|l|}
\hline $\mathrm{g}<0,3$ & Kategori Rendah \\
\hline $0,3 \leq \mathrm{g} \leq 0,7$ & Kategori Sedang \\
\hline $\mathrm{g} \geq 0,7$ & Kategori Tinggi \\
\hline
\end{tabular}

\section{HASIL PENELITIAN}

Analisis Data Peningkatan Kemampuan Pamahaman Matematis Siswa

Data peningkatan kemampuan pemahaman matematis siswa ditinjau dari ujicoba lapangan dapat dilihat pada Tabel 3.1 dan 3.2 berikut

Tabel 3.1. Data Pretes-Postes Ujicoba Lapangan

\begin{tabular}{|l|c|c|c|}
\hline & PRETES & POSTES & GAIN \\
\hline MIN & 45 & 85 & 0.62 \\
\hline MAX & 70 & 100 & 1.00 \\
\hline ST.DEV & 10.79 & 7.06 & \\
\hline RERATA & 68.24 & 86.76 & 0.58 \\
\hline
\end{tabular}

Tabel 3.2. Data Deskriptif Pretes-Postes Ujicoba Lapangan

\section{Descriptive Statistics}

\begin{tabular}{|l|r|r|r|r|r|}
\hline & N & Minimum & Maximum & \multicolumn{1}{c|}{ Mean } & $\begin{array}{c}\text { Std. } \\
\text { Deviation }\end{array}$ \\
\hline Pretes & 34 & 45 & 85 & 68.24 & 10.793 \\
Postes & 34 & 70 & 100 & 86.76 & 7.058 \\
Valid N(liswise) & 34 & & & & \\
\hline
\end{tabular}

Berdasarkan Tabel 3.1 dan 3.2 diperoleh nilai rata-rata pretes yaitu 68,24 sedangkan nilai rata-rata postes yaitu 86,76. Peningkatan rata-rata sebesar 18,52. 
Nilai gain minimal sebesar 0,62 sedangkan nilai gain maksimal sebesar 1,00. Nilai rata-rata gain data kemampuan pemahaman matematis siswa pada ujicoba lapangan sebesar 0,58 (kategori sedang). Data peningkatan kemampuan pemahaman matematis siswa ditinjau dari penyebaran dapat dilihat pada Tabel 3.3 dan 3.4 berikut :

Tabel 3.3. Data Pretes-Postes Penyebaran

\begin{tabular}{|l|c|c|c|}
\hline & PRETES & POSTES & GAIN \\
\hline MIN & 45 & 85 & 0.77 \\
\hline MAX & 70 & 100 & 0.83 \\
\hline ST.DEV & 13.77 & 5.40 & \\
\hline RERATA & 60.33 & 81.33 & 0.53 \\
\hline
\end{tabular}

Tabel 3.4. Data Deskriptif Pretes-Postes Penyebaran

Descriptive Statistics

\begin{tabular}{|l|r|r|r|r|r|}
\hline & N & Minimum & Maximum & Mean & $\begin{array}{c}\text { Std. } \\
\text { Deviation }\end{array}$ \\
\hline Pretes & 30 & 35 & 85 & 60.33 & 13.767 \\
Postes & 30 & 70 & 95 & 81.33 & 5.403 \\
Valid N (listwise) & 30 & & & & \\
\hline
\end{tabular}

Berdasarkan Tabel 3.3 dan 3.4 diperoleh nilai rata-rata pretes yaitu 60.33 sedangkan nilai rata-rata postes yaitu 81.33. Peningkatan rata-rata sebesar 21. Nilai gain minimal sebesar 0,77 sedangkan nilai gain maksimal sebesar 0,83 . Nilai rata-rata gain data kemampuan pemahaman matematis siswa pada penyebaran sebesar 0,53 dengan kategori tinggi. Dengan demikian dapat dinyatakan bahwa dengan menggunakan media pembelajaran matematika berbantuan macromedia flash dalam pembelajaran terkait materi bangun datar dapat meningkatkan kemampuan pemahaman matematis siswa. 


\section{KESIMPULAN DAN SARAN}

\section{Kesimpulan}

Adapun kesimpulan dalam penelitian ini sebagai berikut :

1. Media pembelajaran matematika berbantuan macromedia flash layak untuk dikembangkan dan baik untuk diterapkan dalam pembelajaran.

2. Media pembelajaran berbantuan macromedia flash karena menunjukkan respon yang sangat positif. terhadap kemampuan pemahaman matematis siswa.

3. Media pembelajaran berbantuan macromedia flash menunjukkan respon yang sangat.positif terhadap kemampuan pemahaman matematis siswa.

\section{Saran}

Adapun saran berdasarkan hasil penelitian yang dapat dijadikan bahan pertimbangan adalah :

1. Media pembelajaran Matematika berbantuan macromedia flash perlu diterapkan oleh guru agar pembelajaran menarik dan inovatif.

2. Media pembelajaran Matematika berbantuan macromedia flash perlu dikembangkan pada pokok bahasan yang lain agar dapat mengembangkan berbagai aktivitas dan kreativitas siswa dalam pembelajaran.

3. Perlu adanya penelitian lebih lanjut dengan menerapkan pada pokok bahasan yang berbeda.

\section{DAFTAR PUSTAKA}

Dokumen “Kurikulum 2013 Kompetensi Dasar" Sekolah Dasar (SD)/Madrasah Ibtidaiyah (MI) KEMENTRIAN PENDIDIKAN DAN KEBUDAYAAN 2013

Russeffendy. 1992. Pendidikan Matematika 3. Jakarta: DEPDIKNAS Masykur, Rubhan, dkk. 2017. Pengembangan Media Pembelajaran Matematika dengan Macromedia Flash. Lampung: UIN Raden Intan

Muchlis, Effie Efrida, dkk.2018.Upaya Meningkatkan Kemampuan Pemahaman Konsep Trigonometri Melalui Pendekatan Konstruktivisme dengan Berbantukan Macromedia Flash 8 Pada Mahasiswa Program Studi Pendidikan Matematika FKIP Universitas Bengkulu. Bengkulu: Universitas Bengkulu. 
Rahardjo, Dwi Teguh,dkk .2013. Pengembangan Media Pembelajaran Fisika Menggunakan Macromedia Flash Pada Pokok Bahasan Suhu Dan Kalor.Semarang: UNS.

Risdianto, Eko .2012. Pengaruh Model Pembelajaran Langsung (Direct Instruction) Melalui Media Animasi Berbasis Macromedia Flash Terhadap Minat Belajar Dan Pemahaman Konsep Fisika Siswa di SMA Plus Negeri $7 \quad$ Kota Bengkulu

Sugiyono.2010. Metode Penelitian Kualitatif Kuantitatif dan R\&D. Bandung : Alfabeta

Susanto, Ahmad. 2013. Teori Belajar Pembelajaran. Jakarta: Kencana 